Comment 4

\title{
The Limitations of Logic in Defining the Self
}

\author{
Hubert J.M. Hermans \\ University of NiJMegen, The Netherlands
}

ABSTRACT. Three aspects of Fisher's (1995) logical analysis are criticized: (a) his tendency to separate and polarize points of view in such a way that he provides a misconstrued picture of social constructionism, (b) his adherence to a Cartesian view, with the implication that unity and multiplicity, like continuity and discontinuity, are treated as mutually exclusive rather than as coexistent features of the self, and (c) his conception that narrative has no basis in the body.

I have read Fisher's (1995) contribution with mixed feelings. Concerned as he is with the agency, unity and continuity of the self, he covers an admirable range of theoretical and philosophical literature on the subject, and challenges us to reflect on basic features of the self. At the same time, however, I have to conclude that he is representing a particular (and rather limited) stream of thought that can be labeled as (neo-)Cartesian. His criticism of social constructionism, as represented by the writings of Gergen, Harré and Shotter, is given from that specific angle and, as a consequence, is heavily coloured by it. Such a criticism is a relative one, that is, it says as much about Fisher's philosophical position as it has to say about social constructionism. Given this relativity, I comment on three features that emanate from Fisher's specific perspective: (a) his tendency to separate and polarize points of view, resulting in a caricature of social constructionism, (b) his attempt to preserve a Cartesian view of the self, with the implication that continuity and discontinuity, unity and multiplicity are treated as mutually exclusive instead of coexistent in the functioning self, and (c) his treatment of body and narrative as mutually exclusive, thereby failing to see the far-reaching implications of the notion of 'voice' as an expression of an embodied mind.

\section{Differentiation Instead of Polarization}

It is Fisher's purpose to argue 'that social constructionists do not account for the self, sabotage their own criteria for personal identity and make it

Theory \& Psychology (C) 1995 Sage. Vol. 5(3): 375-382 
impossible to sustain a concept of the person' (p. 324). Let us, in order to get at a more differentiated picture, look, for example, at Harré and Van Langenhove's (1991) plea for the concept of positioning, which they present as a dynamic alternative to the more static concept of role.

\section{Moral and Personal Positioning}

A 'position' in a conversation, for example, is a metaphorical concept through reference to which a person's social and personal attributes as a speaker are compendiously collected. It is possible to position oneself or to be positioned as powerful or powerless, confident or apologetic, dominant or submissive. Positioning is part of the discursive construction of personal stories that make a person's actions intelligible and relatively determinate as social acts.

In providing their arguments for the concept of positioning, Harré and Van Langenhove (1991) make a distinction between 'moral positioning' and 'personal positioning'. Moral positions refer typically to the roles people occupy within a given moral order or to certain institutional aspects of social life. When Smith is a patient and Jones a nurse, it is perfectly clear for both parties when the first asks the second to make her bed. Thus far the conversation between them is organized purely on the basis of role expectations. However, when Smith asks Jones why she has not made her bed yet as she asked her to do, then the story-line between them is likely to shift from moral to personal positioning. In order to answer Smith's question, Jones can no longer refer to her role as a nurse only. She will have to bring in a story that accounts for the deviance of what was expected from her on the basis of her role. Such a story is likely to contain individual particularities (e.g. 'I'm sorry I forgot to make your bed, but I'm a bit confused today as I just received a letter in which ...'). This example, described by Harré and Van Langenhove (1991), shows that the terms 'position' and 'positioning' are sensitive not only to role-related behaviour but also to individual properties and particularities. When Fisher holds that the social constructionists' formulations are 'neo-Meadian' (p. 330), and that specific terms (e.g. 'roles', 'speaking' and 'narrative structures') are hard to disambiguate from Mead's 'generalized other' (p. 330), then such a crude qualification is hardly compatible with Harré's distinction between 'moral positioning' and 'personal positioning'.

\section{Agency and Responsibility}

Similar remarks can be made concerning Gergen's and Shotter's contributions. In a thorough discussion of impasses and evolutions in the psychology of the self, Gergen (1984) says:

How is one to evaluate the general shift from mechanistic to agential explanations in the history of self-inquiry? Surely from the broad cultural 
standpoint there is much to be applauded. Many would argue that the concepts of duty, right, obligation, morality, choice, freedom, and responsibility have played an enormously important role in the emergence of civilized culture. All are obviated if the concept of agency is lost from the vocabulary of understanding persons. (p. 77)

In giving this comment, Gergen approvingly refers to the work of Shotter (1975) on the 'images of man' in psychological research.

A quotation as given above clearly contradicts Fisher's statement that social constructionists 'eclipse individual rights and existences as selves and persons' (p. 344). Of course, more examples could be given, representing contradictions between the writings of Gergen, Harre and Shotter, on the one hand, and the polarizing statements by Fisher, on the other. Instead of giving more examples, it seems more fertile to pose the second issue, the mutual exclusion of unity and multiplicity and of continuity and discontinuity.

\section{Unity and Multiplicity Coexist}

Apparently, Fisher perceives a contradiction between the social constructionists' emphasis on the multiplicity of narrative perspectives and his conception of the unity of the self. In opposition to this view of mutual exclusion of unity and multiplicity, I want to demonstrate that (a) unity and multiplicity coexist in the functioning self, and (b) it is certainly not necessary to lapse into a Cartesian position in order to prevent the self from losing its unity.

\section{Bakhtin's Polyphonic Novel}

Bakhtin (1929/1973), whose contribution is closely related with the basic premises of social constructionism, has explicitly dealt with the relation between unity and multiplicity. Bakhtin has put forward the thesis that Dostoevsky-one of the most brilliant innovators in novelistic literature -created a new form of artistic thought, the polyphonic novel. Such a novel is composed of a number of independent and mutually opposing viewpoints embodied by characters involved in dialogical relationships. Each character is 'ideologically authoritative and independent', that is, each character is perceived as the author of his or her own ideological position, not as an object of Dostoevsky's all-encompassing artistic conception. In this multiplicity of characters and their points of view, Dostoevsky himself is only one of many. Instead of being 'obedient slaves' in the service of Dostoevsky's intentions, the different characters are capable of standing beside their creator, disagreeing with the author, even rebelling against him. 
The hero in Dostoevsky's novels (e.g. Raskolnikov, Myshkin, Stavrogin, Ivan Karamazov) is not simply the object of Dostoevsky's finalizing artistic vision, but comes across as the author of his own ideology. Instead of a multitude of characters subordinated to Dostoevsky's individual vision, there is 'a plurality of consciousnesses', represented by voices who articulate their own position. As in a polyphonic composition, the several voices or instruments have different spatial positions and accompany and oppose each other in a dialogical relation. It is the dialogical relation among the several voices that creates coherence and unity in the story as a whole. In other words, in a polyphonic novel the different characters imply multiplicity, the act of dialogue guarantees their coherence and unity (for the relevance of coherence in narrative thought, see also Gergen \& Gergen, 1988).

\section{Logical vs Dialogical Relationships}

Fisher's contribution appears to me to be a strictly logical analysis of the structure of the self. It may, therefore, be elucidating to establish the difference between logical and dialogical relationships. Bakhtin (1929/ 1973; see also Vasil'eva, 1988) gives an example of two phrases that are completely identical, 'life is good' and again 'life is good'. In terms of Aristotelian logic, these two phrases are related in terms of identity; they are, in fact, one and the same statement. From a dialogical point of view, however, they may be considered as two remarks expressed by the voices of two spatially separated people in communication, who in this case entertain a relationship of agreement. The two phrases are identical from a logical point of view, but different as utterances: the first is a statement, the second a confirmation. In a similar way the phrases 'life is good' and 'life is not good' can be elaborated. In terms of logic, one is a negation of the other. However, as utterances from two different speakers, there is a dialogical relation of disagreement. Bakhtin holds that the relationship of agreement and disagreement is, like question and answer, basically dialogical. Note that Bakhtin does not reject the rules of logic: 'Dialogical relationships are totally impossible without logical and concrete semantic relationships, but they are not reducible to them; they have their own specificity' (p. 152).

\section{The Self from a Dialogical Perspective}

On the basis of Bakhtin's notion of the polyphonic novel, Hermans, Kempen and Van Loon (1992) conceptualized the self in terms of a dynamic multiplicity of relatively autonomous $I$-positions in an imaginal landscape: 
The $I$ has the possibility to move, as in a space, from one position to the other in accordance with changes in situation and time. The $I$ fluctuates among different and even opposed positions. The $I$ has the capacity to imaginatively endow each position with a voice so that dialogical relations between positions can be established. The voices function like interacting characters in a story. Once a character is set in motion in a story, the character takes on a life of its own and thus assumes a certain narrative necessity. Each character has a story to tell about experiences from its own stance. As different voices these characters exchange information about their respective $M e$ s and their worlds, resulting in a complex, narratively structured self. (pp. 28-29)

In the conceptualization phrased above, the multiplicity of the self does not result in fragmentation, because it is the same $I$ that is moving back and forth between several positions. Thanks to this identity, the 'invariance of the self' that is so much of a concern to Fisher is preserved. In other words, variance and invariance, or continuity and discontinuity, coexist in the functioning self. Indeed, it is one and the same $I$ 'who runs the house' (Fisher, p. 333).

On the basis of the coexistence of continuity and discontinuity, it is possible to make a meaningful distinction between the normal multiplicity of the mind and the abnormal state of multiple personality. As Watkins (1986) has argued, in the case of the fragmented self of a multiple personality patient, there is no imaginal dialogue, only sequential monologue. At some moment in time, the person identifies with or is taken over by only one character, which dominates the self. Paradoxically, the illness of multiple personality is problematic because of its singleness of voice at any one moment, not because of its multiplicity. In the normal case there is enough 'invariance of the self' to synthesize the experiences that result from the temporal changes the self goes through (see also Harré, 1991).

\section{The Self as a Personal Consciousness}

In dialogical relationships, the communicating voices are highly personal. Bakhtin (1929/1973) observes that Dostoevsky's world is 'profoundly personalized' and that each character is a 'concrete consciousness, embodied in the living voice of an integral person' (p. 7). A particular utterance is never isolated from the consciousness of a particular character. And because one particular character is always implicitly or explicitly responding to another character, 'a dialogical reaction personifies every utterance to which it reacts' (p. 152).

In the above summary of Bakhtin's view, several notions come together that play a central role in Fisher's contribution: person, consciousness and unity (integrity). In Bakhtin's view these notions do not contradict in any way the notions of narrative, voice and multiplicity that are described by Fisher as typical properties of the social constructionist approach. 


\section{The Thorny Problem of the Body's Relation to the Self}

In his discussion of the role of the body, Fisher holds that for social constructionists thought is 'more Meadian than Mead was ready to allow' (p. 330). Fisher explains that for Mead personal beliefs can be a function of basic attitudinal tendencies, inherent in personal biological nature. In this way Mead creates a loophole that allows him to juxtapose mind/body concepts (Fisher, pp. 329-330). Arguing that the social constructionists eliminate Mead's loophole, Fisher gives as an example the way social constructionists deal with emotions: 'Emotions are not tied to the bodyrather they are historically determined by social values and narratives' (p. 330). Apparently, Fisher sees a contradiction between notions of the body and narrative accounts of the self. In the following, I present three arguments why I think Fisher goes too far in separating body from narrative.

First, advocates of a narrative approach have not only emphasized the role of time, but also argued that space is an intrinsic constituent of narrative. Bruner (1986) proposes that the narrative mode strives to put the (general) human condition into the particulars of experience, and attempts to locate experience in time and space (p. 13). Sarbin (1986) also considers the narrative as a way of organizing episodes, actions and accounts of actions in time and space, and as an achievement that brings together mundane facts and fantastic creations (p. 9). These statements are in apparent contradiction with a Cartesian perspective. For Descartes, the self is part of thinking (res cogitans), whereas the body is part of extension (res extensa). In other words, for Descartes, spatial characteristics do not belong to the self. For the narrativists, on the contrary, spatial characteristics are intrinsic to narrative conceptions of the self.

Second, the notion of (embodied) voice is closely related to narrative because narratives assume a communicative context. That is, there is a person who tells a story and a person who listens to it. Conceived in this way, telling a story is a dialogical act and the person who tells the story is a dialogical narrator (Hermans \& Kempen, 1993). For Bakhtin, the notion of dialogue makes it possible to differentiate the inner world of one and the same individual in the form of an interpersonal relationship. By transforming an 'inner' thought of a particular character into a (bodily) utterance, dialogical relations spontaneously occur between this utterance and the utterance of imaginal others. Dostoevsky's novel The Double may serve as an example. In this novel the second hero (the double) was introduced as a personification of the interior voice of the first hero (Golyadkin). The interior voice of the first hero is externalized in a spatially separated opponent, and this instigates a full-fledged dialogue between two independent characters. In Bakhtin's (1929/1973) terms: 'This persistent urge to see all things as being coexistent and to perceive and depict all things side 
by side and simultaneously, as if in space rather than time, leads him [Dostoevsky] to dramatize in space even the inner contradictions and stages of development of a single person' (p. 23; emphasis added).

Third, the developmental origin of dialogical narratives is in bodily acts of echo and imitation. As Fogel (1993) has observed, newborns are able to imitate some simple gestures like mouth opening and tongue protrusion. Seeing the mouth of the mother, the child knows how to move its own mouth. This is certainly a peculiar achievement, as in this period of life the infant does not have a mirror-like body image of itself. This suggests that early in life, prelinguistic forms of dialogue, in the form of imitative acts, play a central role in the functioning of the body.

Taken together, I am impressed with Fisher's thorough and extensive contribution as far as it emphasizes basic features of the self. My main problem is that, in his logical analysis, he seems to establish separations and polarizations in such a way that he fails to reach his own goal, the integration and synthesis of the self.

\section{References}

Bakhtin, M. (1973). Problems of Dostoevsky's poetics (2nd ed.; R.W. Rotsel, Trans.). New York: Ardis. (Original work published 1929.)

Bruner, J.S. (1986). Actual minds, possible worlds. Cambridge, MA: Harvard University Press.

Fisher, H. (1995). Whose right is it to define the self? Theory \& Psychology, 5, 323352.

Fogel, A. (1993). Developing through relationships. Hemel Hempstead: Harvester Wheatsheaf.

Gergen, K.J. (1984). Theory of the self: Impasse and evolution. Advances in Experimental Social Psychology, 17, 49-115.

Gergen, K.J., \& Gergen, M.M. (1988). Narrative and the self as relationship. Advances in Experimental Social Psychology, 21, 17-56.

Harré, R. (1991). The discursive production of selves. Theory \& Psychology, 1, 5163.

Harré, R., \& Van Langenhove, L. (1991). Varieties of positioning. Journal for the Theory of Social Behaviour, 21, 393-407.

Hermans, H.J.M., \& Kempen, H.J.G. (1993). The dialogical self: Meaning as movement. San Diego, CA: Academic Press.

Hermans, H.J.M., Kempen, H.J.G., \& Van Loon, R.J.P. (1992). The dialogical self: Beyond individualism and rationalism. American Psychologist, 47, 23-33.

Sarbin, T.R. (1986). The narrative as a root metaphor for psychology. In T.R. Sarbin (Ed.), Narrative psychology: The storied nature of human conduct (pp. 321). New York: Praeger.

Shotter, J. (1975). Images of man in psychological research. London: Methuen.

Vasil'eva, I.I. (1988). The importance of M.M. Bakhtin's idea of dialogue and dialogic relations for the psychology of communication. Soviet Psychology, 26, $17-31$. 
Watkins, M. (1986). Invisible guests: The development of imaginal dialogues. Hillsdale, NJ: Erlbaum.

Hubert J.M. Hermans is Professor of Personality Psychology at the University of Nijmegen, The Netherlands. Originally publishing on achievement motivation and fear of failure, he constructed several psychometric tests to measure these motives in adults and children. In the mid-1970s he turned away from this field and formulated a theory of the self, called 'Valuation Theory', and devised, in accordance with this theory, a method of self-confrontation. This theory and method have been published in a variety of American and European psychological journals in the 1980s and 1990s. His most recent interest is in the dialogical nature of the self (American Psychologist, January 1992). Publications include The Dialogical Self: Meaning as Movement (with Harry Kempen, Academic Press, 1993) and Self-Narratives: The Construction of Meaning in Psychotherapy (with Els Hermans-Jansen, Guilford Press, 1995). Address: Department of Clinical Psychology and Personality, Montessorilaan 3, 6525 HR Nijmegen, The Netherlands (e-mail: hhermans@psych.kun.nl). 